(p)ISSN: 1907-2333 (e)ISSN: 2685-9211

https:/ljurnal.ucy.ac.id/index.php/agama_islam

Volume 10 Nomor 1, Juni 2020, 59-70

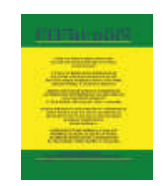

\title{
Peran Guru Dalam Meningkatkan Karakter Religius Murid Di Madrasah Tsanawiyah Nurul Ummah (MTsNU)
}

Difla Nadjih"), Ahmad Nasir Ari Bowo²*), Salamudin3), Candra Audy4), Riduan Harahap5), Siti Utami6), Reni Indrayani'), Firman Saleh8),

Saidi Yako9), Suhaimi'o), Sayuti'11)

1-11) Universitas Cokroaminoto Yogyakarta

1)difnadjih@gmail.com, ${ }^{2)}$ ahmadnasir.aribowo@yahoo.co

*Penulis koresponden

\begin{tabular}{|l|l|l|}
\hline Diajukan: 05-03-2020 & Diterima: 04-06-2020 & Diterbitkan: 19-06-2020 \\
\hline
\end{tabular}

\begin{abstract}
MTs Nurul Ummah (MTsNU) pupils, among others (1) held in the morning and the reading of Asmaul Husna. (2) Dhuha prayer in congregation both pupils and teachers and employees. (3) Islamic activities such as remembrance, istigosah, commemoration of Islamic holidays, haul, and once moved pilgrimage to Wali Sanga or scholars. The obstacle that changes the teacher in improving the religius character of MTsNU pupils is the difference in their character which makes it difficult for teachers to improve the religius character of pupils simultaneously and improve communication between teachers. The solution made by them is that the teachers communicate with each other by sharing, deliberation and holding meetings between teachers both with the dormitory in order to create pupils with religius character.
\end{abstract}

Keywords: Teacher's Role, Religious Character, Pupils

Abstrak: peran guru dalam meningkatkan karakter religius murid MTsNU antara lain (1) diadakan apel pagi dan pembacaan asmaul husna. (2) Shalat dhuha berjamaah baik siswa maupun guru dan karyawan. (3) Kegiatan religius dan keagamaan diantaranyazikir, istigosah, peringatan hari besar Islam, Haul, dan setahun sekali Ziarah ke Wali Sanga atau ahli ulama. Hambatan yang dihadapi oleh guru saat meningkatkan karakter relijius murid MTsNU adalah perbedaan karakter masing-masing siswa yang membuat guru sulit untuk meningkatkan secara bersamaan dan kurangnya komunikasi antar guru. Solusi yang dilakukan guru dalam meningkatkan karakter religius murid MTsNU yaitu para guru saling menjaga komunikasi dengan cara sharing pengalaman, musyawarah bersama dan mengadakan rapat bulanan antar guru maupun dengan pondok demi terciptanya siswa yang berkarakter religius Islam.

Kata Kunci: Peran Guru, Karakter Religius, Murid 


\section{A. Pendahuluan}

Tugas dan peran guru di Indonesia kemudian menjadi semakin berat. Zaman milenial telah melahirkan sejumlah tantangan antar generasi yang tidak bisa disepelekan dan harus disikapi secara profesional. ${ }^{1}$ Kepesatan perkembangan informasi, pengetahuan dan teknologi telah menuntut manusia menjadi cerdas dan terampil, dalam iman dan taqwa. ${ }^{2}$ Apabila tidak demikian, arus sesat dari milenial dan modernisasi akan menenggelamkannya.

Sebagai generasi masa depan bangsa Indonesia yang beragama, persiapan anak bangsa untuk memiliki karakter religius yang berdaya tahan dalam persaingan global serta berkeahlian di bidang yang diminati adalah mutlak. 3 Pendidikan telah diakui sebagai faktor determinan. Hal demikian sesuai tujuan utama pendidikan Islam Indonesia untuk mengembangkan potensi murid agar menjadi insan beriman dan bertaqwa kepada Allah SWT dalam wawasan kebangsaan.4 Muslim yang berkarakter mulia, berjasmani sehat, berfikir cerdas, kreatif, berjiwa mandiri sehingga bisa menjadi WNI demokratis bertanggung jawab.5 Marzuki bahkan menekankan pendidikan Islam tetap dibutuhkan untuk mewujudkan misi utama kemanusiaan dalam garis Allah dan Rasul-Nya sehingga insan kamil terwujud. 6

1 Kusnandar, Guru Profesional: Implementasi Kurikulum Tingkat Satuan Pendidikan (KTSP) Dan Sukses Dalam Sertifikasi Guru (Jakarta: Rajawali Press, 2007).

2 Ahmad Nasir Ari Bowo, "Perilaku Menyimpang Siswa SMA (Studi Eksplorasi Peta Dan Faktor-Faktor Penyebab Perilaku Menyimpang Di SMA Negeri Jumapolo)," Academy of Education Journal 4, no. 2 (2013); Ahmad Nasir Ari Bowo, "Pengembangan Pengelolaan Pembelajaran Ekonomi Berbasis Lingkungan Dengan Strategi Small Group Discussion Di SMA Muhammadiyah 1 Surakarta," Academy of Education Journal 6, no. 1 (2015).

3 Miftachul Alfin and Fattah Setiawan Santoso, "Strategi Pengembangan Perguruan Tinggi Agama Islam Sebagai Organisasi Pembelajaran," Ulumuddin : Jurnal Ilmu-ilmu Keislaman 3, no. 2 (2013): 54-67.

4 Umi Musaropah, "Pendidikan Kebangsaan Dalam Pesantren Perspektif Abdul Wahid Hasyim," Ulumuddin: Jurnal Ilmu-ilmu Keislaman 9, no. 1 (2019): 1-22.

5 Republik Indonesia, Undang-Undang RI Nomor 20 Tahun 2003 Tentang Sistem Pendidikan Nasional, n.d.

${ }^{6}$ Marzuki, Pendidikan Karakter Islam, (Jakarta: Amzah, 2015). 
Penyelenggaraanya pun tidak bisa sebatas pendidikan anak usia dini,7 namun harus berjenjang hingga perguruan tinggi. Kunaepi menegaskan pijakan kepada nilai-nilai dasar tersebut bisa dimodifikasi sesuai nilai-nilai di sekolah masing-masing. ${ }^{8}$

Secara langsung dan tidak langsung semua tantangan tersebut memerlukan penyelesaian dengan peran guru dalam pendidikan karakter. Krisis moral, krisis sosial, dan krisis identitas menunjukan pola anak muslim Indonesia yang sedang kehausan akan asupan nilai-nilai kehidupan. ${ }^{9}$ Diantanya, tawuran antar pelajar, pergaulan bebas, merokok di lingkungan sekolah, konsumsi obat terlarang. di masa sekarang ini juga banyak siswa yang tidak menjalankan kewajiban puasa Ramadan. Banyak dari mereka bahkan kurang menghormati orang tua dalam kehidupan keseharian. ${ }^{10}$ Oleh karena itu, peran guru akan sangat menentukan dalam melahirkan manusia-manusia yang mampu menghadapi tantangan di masa global ini. ${ }^{11}$

Perkembangan negatif dalam pergaulan anak usia remaja juga dirasakan di MTsNU. Sekolah yang seatap dengan Madrasah Aliyah Nurul Ummah ini memiliki kekhasan dengan konsistensi tahfid Quran secara berjenjang. ${ }^{12}$ Secara kasat mata maka, pendidikan MTsNU tidak diragukan sebagai pengemban misi pendidikan Akhlak Islami. Bahkan dengan corak keislaman yang dekat dengan pesantren Nahdhatul Ulama yang dekat

7 Setiani and Difla Nadjih, "Pembentukan Karakter Anak Usia Dini Melalui Pendidikan Agama Islam Di TK ABA Kalibulus Rogobangsan Bimomartani Ngemplak Sleman," Ulumuddin: Jurnal Ilmu-ilmu Keislaman 6, no. $2^{`}$ (2016): 125-136.

8 Aang Kunaepi, "Revitalisasi Pendidikan Karakter Melalui Internalisasi PAI Dan Budaya Relijius," Jurnal At-Taqaddum 5, no. 2 (2013): 350-372.

9 Bowo, "Perilaku Menyimpang"; Ahmad Nasir Ari Bowo, "Small Group Discussion Berbasis Readig Guide Untuk Meningkatkan Keaktifan Dan Hasil Belajar PKn Siswa MTs," Academy of Education Jourmal 5, no. 2 (2014).

10 Bowo, "Perilaku Menyimpang."

11 Bowo, "Pengembangan Pengelolaan"; Nurul Fatihah and Difla Nadjih, "Hubungan Pendidik Dan Terdidik Dalam Al-Quran," Ulumuddin: Jurnal Ilmu-ilmu Keislaman 7, no. 2 (2017): 73-86.

12 Ahlan Abdullah Solo, Taufik Nugroho, and Difla Nadjih, "Upaya Santri Dalam Pemeliharaan Hafal Al- Qur'an Di MANU Kota Gede Yogyakarta," Ulumuddin: Jurnal Ilmu-ilmu Keislaman 8, no. 2 (2018): 131-140. 
dengan charisma kyai, ${ }^{13}$ bisa menjadi indikator bahwa pendidikan watak yang dikembangkan juga menanamkan persatuan bangsa. ${ }^{14}$

Meski demikian, berdasarkan hasil wawancara awal penelitian dengan guru dapat diketahui bahwa ada permasalahan karakter siswa MTsNU sekarang ini. Beberapanya adalah; Siswa yang kurang disiplin antara lain terlambat masuk sekolah, tidak mengikuti apel pagi, tidak mengikuti shalat duha berjamaah, siswa yang jarang masuk sekolah, perkelahian siswa, siswa yang berpacaran. Dari sisi material karakter keislaman, banyak muridnya saat ini masih belum mampu membaca AlQur'an secara baik. Rutinitas shalat lima waktu belum terlaksana secara teratur, apalagi penunaian puasa di bulan Romadhan.

Semua penyimpangan social keagamaan itu tentu berdampak pada sikap dalam kehidupan sehari-hari, selanjutnya menjadi masalah serius di kemudian hari. Karena itu tidak berlebihan bila ada kesimpulan umum sebagai salah satu satu sebab utama dari perilaku amoral pelajar yang timbul sekarang adalah kekurangan dalam pendidikan karakter religius. ${ }^{15}$ Dalam pendidikan Islam di Sekolah, Peran Guru PAI menjadi berperan penting dalam implementasinya. ${ }^{16}$

\section{B. Metode Penelitian}

Tujuan Penelitian pendidikan karakter di MTsNU dilakukan untuk; (1) mengetahui pendidikan karakter religius bagi pelajar peserta didik MTsNU. (2) Mengetahui hambatan guru PAI saat menjalankannya bagi siswa peserta didik MTsNU. (3) Mengetahui upaya tindak lanjut dari para guru untuk menyelesaikan problematika pendidikan karakter keagamaan bagi para murid peserta didik di MTsNU.

Penelitian kualitatif yang ingin memotret situasi natural obyek, sehingga penelitian ini tidak bisa dikategorikan sebagai pengelitian

13 Umi Musaropah, "Kharisma Kyai Dalam Organisasi Pendidikan Pesantren Tradisional," Ulumuddin: Jurnal Ilmu-ilmu Keislaman 8, no. 2 (2018): 141-155.

14 Musaropah, "Pendidikan Kebangsaan."

15 Taufik Nugroho, "Analisis Manajemen Pendidikan Terhadap Kualitas Madrasah Indonesia," Ulumuddin: Jurnal Ilmu-ilmu Keislaman 6, no. 2 (2016): 80-87.

16 Rozib Sulistiyo, "Penguatan Peran Guru Pendidikan Agama Islam Dalam Penanaman Akhlak Di Sekolah," Ulumuddin: Jurnal Ilmu-ilmu Keislaman 6, no. 1 (2016): 1-10; Fatihah and Difla Nadjih, "Hubungan Pendidik Dan Terdidik Dalam AlQuran." 
tindakan kelas. ${ }^{17}$ kemudian dipilih dengan subyek terdiri dari; Kepala Sekolah, Guru Pendidikan Agama Islam (PAI) dan Siswa- siswi kelas VIII serta personil lain yang dianggap perlu. data utama meliputi hasil dokumentasi dan wawancara mendalam dengan interview guide. Pelaksanaannya diantara awal bulan Oktober tahun 2019 hingga bulan Januari 2020. Dalam menganalisa data, analisis deskriptif kualitatif secara induktif dan deduktif. ${ }^{18}$ Induktif dimana pengambilan kesimpulan yang berpangkal dari hal ataupun peristiwa khusus kepada yang umum. Kesimpulan Deduktif berpijak dari suatu kejadian atau peristiwa yang bersifat umum kemudian diarahkan kepada yang lebih khusus.

\section{Tinjauan tentang Peran Guru dalam Meningkatkan Karakter Religius}

1. Peran

Peranan guru dalam uraian ini mengikuti pengertian Sahertian dan Sahertian. Keterlibatannya secara aktif dalam proses kerja dalam proses penampilan dimana ia tampil sebagai sesuatu yang diperankan. ${ }^{19}$ Pengertian demikian tidak berbeda jauh dengan yang ditampilkan secara bahasa dalam Kamus Besar Bahasa Indonesia. Perangkat tingkah yang diharapkan dimiliki oleh orang yang berkedudukan dalam masyarakat. ${ }^{20}$

Banyak ahli setuju dengan pernyataan tentang peran yang berbanding lurus dengan dinamika dari keberadaan status ataupun seseorang dalam tatanan sosial masing-masing. Bagi Barbara, dinamika itu berupa seperangkat tingkah laku yang diharapkan oleh orang lain terhadap seseorang sesuai kedudukannya dalam suatu sistem. ${ }^{21}$

Karena itu, setiap orang bisa mempunyai beragam peran saat berhadapan dengan masyarakat di sekitarnya. Pengertiannya menjadi

${ }_{17}$ Agung Prihantoro and Fattah Hidayat, "Melakukan Penelitian Tindakan Kelas," Ulumuddin: Jurnal Ilmu-ilmu Keislaman 9, no. 1 (2019): 49-60.

${ }_{18}$ Anas Sudijono, Pengantar Statistik Pendidikan (Jakarta: Rajawali Pers, 1987).

19 Piet Sahertian dan Aleida Sahertian, Supervisi Pendidikan Dalam Rangka Program Inservice Education, jakarta, PT Rineka Cipta, 1992, hlm 34

20 Piet Sahertian and Aleida Sahertian, Supervisi Pendidikan Dalam Rangka Program Inservice Education (Jakarta: PT Rineka Cipta, 1992).

${ }^{21}$ Bowo, "Small Group Discussion Berbasis Readig Guide Untuk Meningkatkan Keaktifan Dan Hasil Belajar PKn Siswa MTs"; Bowo, "Pengembangan Pengelolaan Pembelajaran Ekonomi Berbasis Lingkungan Dengan Strategi Small Group Discussion Di SMA Muhammadiyah 1 Surakarta." 
penentu terhadap kepputusan seseorang dalam bertindak di lingkungannya. kesempatan, peluang dan perubahan yang diberikan oleh masyarakat kepada sseseaorang juga tergantung dengan perannya. Dengan demikian, peran memeiliki hubungan kuat dengan norma sosial yang berjalan.

Dalam Pidarta kemudian peranan guru atau pendidik dijabarkan, antara lain; manajer pendidikan atau pengorganisasian kurikulum, fasilitator pendidikan, Pelaksana pendidikan, Pembimbing dan supervisior, Penegak disiplin, model dan perilaku yang akan ditiru siswa. Selain itu, ia juga berperan sebagai konselor, penilai, petugas tata usaha tentang administrasi kelas yang diajarnya. Ia bahkan bisa menjadi komunikator denganorang tua siswa dengan masyarakat termasuk di dalamanya peran pengajar peningkatan berkelanjutan dalam keprofesionalan disamping keanggotaaan dalam organisasi profesi. ${ }^{22}$

2. Guru

Guru merupakan orang yang pekerjaan, mata pencaharian atau profesinya adalah mengajar. ${ }^{23}$ dalam bahasa arab dikenal dikenal dengan al-mu'allim atau al-ustadz. Dalam bahasa Inggris biasa disebut dengan teacher.

Dalam konteks pendidikan Islam, ia bertugas memberikan ilmu dalam majelis taklim. Pengajaran berarti pemberian ilmu. Hal itu sesuai dengan Pendapat klasik yang mengartikannya orang yang pekerjaanya mengajar, dimana hanya menekankan satu sampingan selain pendidik dan pelatih. Dalam dinamika selanjutnya, pengertian guru telah tumbuh meluas.

Sebagai pendidik profesional, guru telah mendapat amanat dari orang tua wali memajukan akhlak dan melausakan ketrampilan pengatahuan anak. Tugas utama mendidik, mengajar, membimbing, mengarahkan, melatih, menilai dan mengevaluasi siswa pada pendidikan anak usia dini jalur pendidikan formal, pendidikan dasar, dan menengah.

${ }^{22}$ Jamil Suprihatiningrum, Guru Profesional Pedoman Kinerja, Kualifikasi Dan Kompetensi Guru (Yogyakarta: Ar-Ruzz Media, 2013).

23 https://kbbi.kemdikbud.go.id/entri/guru 
Di perundangan pendidikan Indonesia, mereka itu yang memperoleh surat keputusan (SK), baik dari pemerintah atau swasta untuk melaksanakan tugasnya, dan karena itu memiliki hak dan kewajiban untuk melaksanakan kegiatan pembelajaran di lembaga pendidikan sekolah. Ia memiliki kemampuan merancang program pembelajaran, serta mampu menata dan mengolah kelas agar siswa dapat belajar dan pada akhirnya dapat mencapai tingkat kedewasaan sebagai tujuan akhir dari proses pendidikan. ${ }^{24}$

3. Karakter

Secara bahasa memiliki kesamaan arti dengan tabiat; watak. sifatsifat kejiwaan, akhlak atau budi pekerti yang membedakan seseorang dari yang lain. ${ }^{25}$ Itulah keadaan sebenarnya dari dalam diri seseorang yang membedakan dengan yang lain. Asal katanya dari bahasa Yunani, karasso, berarti cetak biru, format dasar, sidik termasuk sidik jari. Dalam istilah Inggris, character is all the mental and moral qualities that make a person, group of people, and places different from other. ${ }^{26}$ Hornby dan Parnwell, secara harfiah berarti kualitas mental atau moral, kekuatan moral, nama atau reputasi. 27

Di terminologi Islam kemudian ditemukan ada kesepadanan dengan akhlak. Al Ghazali menunjukkannya sebagai perangai yang menetap dalam jiwa seseorang dan sumber dari munculnya perbuatan-perbuatan tertentu dari dirinya secara mudah dan ringan tanpa dipikirkan atau direncanakan sebelumnya. ${ }^{28}$

Pada khasanah kearifan lokal Indonesia, Ki Hadjar Dewantara menjadi tokoh penting pendidikan karakter. Karakter sepadan dengan watak sebagai paduan dari pada segala tabiat manusia yang bersifat tetap

24 Suprihatiningrum, Guru Profesional Pedoman Kinerja, Kualifikasi Dan Kompetensi Guru.

25 https://kbbi.kemdikbud.go.id/entri/karakter

26 Siswanto, "Pendidikan Karakter Berbasis Nilai-Nilai Relijius," Tadris: Jurnal Pendidikan Islam 8, no. 1 (2003): 91 - 107; Sulistiyo, "Penguatan Peran Guru Pendidikan Agama Islam Dalam Penanaman Akhlak Di Sekolah."

27 Abdul Jalil, "Karakter Pendidikan Untuk Membentuk Pendidikan Karakter," Nadwa : Jurnal Pendidikan Islam 6, no. 2 (2016): 175-194.

28 Zubaedi, Desain Pendidikan Karakter: Konsepsi Dan Aplikasi Dalam Lembaga Pendidikan (Jakarta: Kencana, 2011). 
sehingga menjadi tanda yang khusus sehingga bisa membedakan seorang dari yang lain. ${ }^{29}$ Sifat alamiah itu bisa berkembang setelah pengaruh pengajaran yang menyeimbangkan secara tetap antara hidup batin dengan perbuatan lahir seseorang.30 Driyakara ada kecenderungan sama dengan pendahulunya terhadap eksistensi alamiah dari karakter namun perlu dibiasakan sehingga seseorang bisa berbudi pekerti. ${ }^{31}$

Dari beberapa pengertian diatas, secara sederhana, karakter dapat simpulkan. Nilai-nilai dan sikap hidup yang positif, yang dimiliki seseorang sehingga memengaruhi tingkah laku, cara berfikir dan bertindak orang itu, dan akhirnya menjadi tabiat hidupnya.

4. Religius

Artinya adalah sifat keagamaan. ${ }^{2}$ Partanto dan Al-Barry membahasakannya sebagai ketaatan, ibadah, dan iman.33 Awal Penyerapannya di awali untuk mengartikan tatanan dalam lingkup keagamaan tertentu, Nasrani. Penyerapannya sebagai istilah umum untuk semua baru ada setelah diterima dalam pergaulan di Nusantara.

Meski demikian ada yang membedakan antara Istilah religi dan din yang cenderung sama untuk mengistilahkan agama. Bagi Ali, Asal katanya adalah Relegree yang berarti berpegang kepada norma-norma. dalam arti, arti sebenarnya terbatas dalam orde agama pembawa awalnya terbatas pada pengertian relasi manusia dan Tuhan saja. Dalam dinul Islam bermakna lebih luas, sebab selain memiliki hubungan yang erat dengan Tuhan yang berhubungan secara vertical, juga hubungan antar manusia dan alam lingkungan hidupnya yang berdimensi hubungan horizontal.34

5. Guru PAI dan Pendidikan karakter religius

${ }^{29}$ Hadjar Dewantara, Kebudayaan (II) (Yogyakarta: UST Press, 2013). 2015)

3o Paul Suparno, Pendidikan Karakter Di Sekolah (PT Kanisius: Yogyakarta,

${ }^{31}$ Sudiarja et al., eds., Karya Lengkap Driyarkara; Esai-Esai Pemikiran Yang Terlibat Penuh Dalam Perjuangan Bangsanya (Jakarta: Gramedia, 2006).

32 https://kbbi.kemdikbud.go.id/entri/religius

33 Pius. A.Partanto and M. Dahlan Al-Barry, Kamus Ilmiyah Populer (Surabaya: Apollo, 2005).

34 Mohammad Daud Ali, Pendidikan Agama Islam (Jakarta: Rajawali Pers, 1998); Andrian M. Dupuis and Robert B. Nordberg, Philosophy And Education, : A Total View (The Bruce Publisihing Company: USA, 1973). 
Muatan pendidikan Islam berupa akhlak yang mencerminkan keberimanan terhadap Tuhan yang Maha Esa. Perwujudannya ada dalam perilaku dan tindakan ajaran agama dan kepercayaan yang dianut dengan menghargai perbedaan agama hidup rukun dan damai dengan pemeluk agama lain.35 Guru PAI menjadi berperan penting di dalamnya kemudian perlu memahami perannya.

Suyatno merangkum pendapat beberapa pakar pendidikan karakter tentang peran guru. 36

a. Guru terlibat aktif dalam proses pembelajaran, diskusi, dan mengambil inisiatif sebagai upaya membangun pendidikan karakter.

b. Guru penanggung jawab menjadi model yang memiliki nilai-nilai moral dan memanfaatkan kesempatan untuk mempengaruhi siswasiswanya.

c. Guru memberikan pemahaman bahwa karakter siswa tumbuh melalui kerja sama dan berpartisipasi dalam mengambil keputusan.

d. guru perlu melakukan refleksi atas masalah moral berupa pertanyaanpertanyaan rutin untuk memastikan bahwa siswa-siswanya mengalami perkembangan akhlak dan berkarakter.

e. Pendidik perlu menjelaskan atau mengklarifikasikan kepada murid secara terusmenerus tentang berbagai nilai yang baik dan yang buruk.

Dalam konteks demikian, Zubaidi dari Sudrajat seorang guru harusnya dapat menjalankan 5 peran pengajaran.37 Pertama, konservatoir bertujuan pemeliharan sistem nilai yang merupakan sumber norma kedawasaan. Kedua, innovator yang mengembangkan sistem nilai ilmu pengetahuan. Ketiga, transmitter untuk meneruskansistem-sistem nilai ini kepada murid. Keempat, transformator dengan menerjemahkan sistem-sistem nilai ini melalui penjelmaan dalam pribadinya dan perilakunya, dalam proses interaksi dengan murid. Peran terakhir sebagai organisator untuk menciptakan proses edukatif, baik secara formal

35 Tim Penyusun Buku, Konsep Dan Pedoman Penguatan Pendidikan Karakter (Jakarta: Kementerian Pendidikan dan Kebudayaan RI, 2015).

${ }^{36}$ Suyatno, Urgensi Pendidikan Karakter (Jakarta: Depdiknas, 2009).

37 Zubaedi, Desain Pendidikan Karakter: Konsepsi Dan Aplikasi Dalam Lembaga Pendidikan. 
terhadap pihak yang mengangkat dan menjelaskan) maupun sasaran didik, serta Tuhan yang menciptakannya secara normal.

Proses belajar mengajar merupakan inti dari proses pendidikan secara keseluruhan dengan guru sebagai pemegang peranan utama. Karena proses belajar mengajar mengandung serangkaian perbuatan pendidik/guru dan siswa atas dasar hubungan timbal balik yang berlangsung dalam situasi edukatif untuk mencapai tujuan tertentu. Interaksi atau hubungan timbal balik antara guru dan siswa itu merupakan syarat utama bagi berlangsungnya prose belajar mengajar. Interaksi dalam peristiwa belajar mengajar ini memiliki arti yang lebih luas, tidak sekedar hubungan antara guru dan siswa tetapi berupa interaksi edukatif. Dalam hal ini bukan hanya penyampaian peran berupa materi pelajaran, melainkan menanamkan sikap dan nilai pada iri siswa yang sedang belajar.

\section{Pendidikan Karakter di MTsNU}

1. Peran guru dalam meningkatkan karakter religius siswa

Untuk meningkatkan karakter religius siswa di MTsNU setiap hari diadakan apel pagi dan pembacaan asmaul husna, kemudian diikuti dengan shalat dhuha berjamaah baik siswa maupun guru dan karyawan. MTsNU juga mengadakan kegiatan religius diantaranyazikir, istigosah, peringatan hari besar Islam, Haul, dan setahun sekali Ziarah ke Wali Sanga atau ahli ulama.

2. Kendala yang dihadapi oleh guru.

Dalam meningkatkan karakter religius siswa, Kendala yang dihadapi guru dalam meningkatkan karakter religius siswa di MTsNU adalah perbedaan karakter siswa yang dihadapi oleh guru yang membuat guru sulit untuk meningkatkan karakter religius siswa secara bersamaan dan kurangnya komunikasi antar guru sehingga mengakibatkan miskomunikasi.

3. Solusi Guru

Dalam mengatasi kendala yang dihadapi oleh guru dalam meningkatkan karakter religius siswa, Para guru saling menjaga komunikasi dengan cara sharing, musyawarah bersama dan mengadakan 
rapat bulanan antar guru maupun dengan pondok/asrama.agar terciptanya siswa yg religius.

\section{Daftar Pustaka}

A.Partanto, Pius., and M. Dahlan Al-Barry. Kamus Ilmiyah Populer. Surabaya: Apollo, 2005.

Alfin, Miftachul, and Fattah Setiawan Santoso. "Strategi Pengembangan Perguruan Tinggi Agama Islam Sebagai Organisasi Pembelajaran.” Ulumuddin : Jurnal Ilmu-ilmu Keislaman 3, no. 2 (2013): 54-67.

Ali, Mohammad Daud. Pendidikan Agama Islam. Jakarta: Rajawali Press, 1998.

Anas Sudijono. Pengantar Statistik Pendidikan. Jakarta: Rajawali Pers, 1987.

Andrian M. Dupuis, and Robert B. Nordberg. Philosophy And Education, : A Total View. The Bruce Publisihing Company: USA, 1973.

Bowo, Ahmad Nasir Ari. "Pengembangan Pengelolaan Pembelajaran Ekonomi Berbasis Lingkungan Dengan Strategi Small Group Discussion Di SMA Muhammadiyah 1 Surakarta." Academy of Education Journal 6, no. 1 (2015).

- - . "Perilaku Menyimpang Siswa SMA (Studi Eksplorasi Peta Dan Faktor-Faktor Penyebab Perilaku Menyimpang Di SMA Negeri Jumapolo)." Academy of Education Journal 4, no. 2 (2013).

--—. "Small Group Discussion Berbasis Readig Guide Untuk Meningkatkan Keaktifan Dan Hasil Belajar PKn Siswa MTs." Academy of Education Journal 5, no. 2 (2014).

Dewantara, Hadjar. Kebudayaan (II). Yogyakarta: UST Press, 2013.

Fatihah, Nurul, and Difla Nadjih. "Hubungan Pendidik Dan Terdidik Dalam Al-Quran.” Ulumuddin: Jurnal Ilmu-ilmu Keislaman 7, no. 2 (2017): $73-86$. https://jurnal.ucy.ac.id/index.php/agama_islam/article/view/188.

Indonesia, Republik. Undang-Undang RI Nomor 20 Tahun 2003 Tentang Sistem Pendidikan Nasional, n.d.

Jalil, Abdul. "Karakter Pendidikan Untuk Membentuk Pendidikan Karakter.” Nadwa : Jurnal Pendidikan Islam 6, no. 2 (2016): 175194.

http://journal.walisongo.ac.id/index.php/Nadwa/article/view/586.

Kunaepi, Aang. "Revitalisasi Pendidikan Karakter Melalui Internalisasi PAI Dan Budaya Relijius.” Jurnal At-Taqaddum 5, no. 2 (2013): 350-372.

http://journal.walisongo.ac.id/index.php/attaqaddum/article/view $/ 704$.

Kusnandar. Guru Profesional: Implementasi Kurikulum Tingkat Satuan Pendidikan (KTSP) Dan Sukses Dalam Sertifikasi Guru. Jakarta: Rajawali Press, 2007.

Marzuki. Pendidikan Karakter Islam,. Jakarta: Amzah, 2015.

Musaropah, Umi. "Kharisma Kyai Dalam Organisasi Pendidikan Pesantren Tradisional." Ulumuddin: Jurnal Ilmu-ilmu Keislaman 8, no. 2 (2018): 141-155. 
- - . "Pendidikan Kebangsaan Dalam Pesantren Perspektif Abdul Wahid Hasyim.” Ulumuddin: Jurnal Ilmu-ilmu Keislaman 9, no. 1 (2019): 1-22.

Nugroho, Taufik. "Analisis Manajemen Pendidikan Terhadap Kualitas Madrasah Indonesia." Ulumuddin: Jurnal Ilmu-ilmu Keislaman 6, no. 2 (2016): 80-87.

Prihantoro, Agung, and Fattah Hidayat. "Melakukan Penelitian Tindakan Kelas.” Ulumuddin: Jurnal Ilmu-ilmu Keislaman 9, no. 1 (2019): 49-6o.

Sahertian, Piet, and Aleida Sahertian. Supervisi Pendidikan Dalam Rangka Program Inservice Education. Jakarta: PT Rineka Cipta, 1992.

Setiani, and Difla Nadjih. "Pembentukan Karakter Anak Usia Dini Melalui Pendidikan Agama Islam Di TK ABA Kalibulus Rogobangsan Bimomartani Ngemplak Sleman." Ulumuddin: Jurnal Ilmu-ilmu Keislaman 6, no. $2^{`}$ (2016): 125-136.

Siswanto. "Pendidikan Karakter Berbasis Nilai-Nilai Relijius." Tadris: Jurnal Pendidikan Islam 8, no. 1 (2003): 91 - 107.

Solo, Ahlan Abdullah, Taufik Nugroho, and Difla Nadjih. "Upaya Santri Dalam Pemeliharaan Hafal Al- Qur'an Di MANU Kota Gede Yogyakarta." Ulumuddin: Jurnal Ilmu-ilmu Keislaman 8, no. 2 (2018): 131-140.

Sudiarja, Budi Subanar, Sunardi, and Sarkim, eds. KaryaLengkap Driyarkara; Esai-Esai Pemikiran Yang Terlibat Penuh Dalam Perjuangan Bangsanya. Jakarta: Gramedia, 2006.

Sulistiyo, Rozib. "Penguatan Peran Guru Pendidikan Agama Islam Dalam Penanaman Akhlak Di Sekolah.” Ulumuddin: Jurnal Ilmu-ilmu Keislaman 6, no. 1 (2016): 1-10.

Suparno, Paul. Pendidikan Karakter Di Sekolah. PT Kanisius: Yogyakarta, 2015.

Suprihatiningrum, Jamil. Guru Profesional Pedoman Kinerja, Kualifikasi Dan Kompetensi Guru. Yogyakarta: Ar-Ruzz Media, 2013.

Suyatno. Urgensi Pendidikan Karakter. Jakarta: Depdiknas, 2009.

Tim Penyusun Buku. Konsep Dan Pedoman Penguatan Pendidikan Karakter. Jakarta: Kementerian Pendidikan dan Kebudayaan RI, 2015.

Zubaedi. Desain Pendidikan Karakter: Konsepsi Dan Aplikasi Dalam Lembaga Pendidikan. Jakarta: Kencana, 2011. 